\title{
FACTORS ASSOCIATED WITH TB-HIV/AIDS \\ CO-INFECTION IN KEDU, CENTRAL JAVA
}

\author{
Tuti Susilowati1), Tri Nur Kristina'), Muchlis AU Sofro3) \\ 1)Doctoral Program in Medical and Health Sciences, Universitas Diponegoro \\ 2)Faculty of Medicine, Universitas Diponegoro \\ 3)Dr Karyadi General Hospital Semarang, Central Java
}

\begin{abstract}
Background: TB-HIV co-infection is one of the current biggest public health challenges in the world. Although there is a breadth of information on TB-HIV coinfection among settled populations elsewhere, to our knowledge, there are no published reports on the determinants of TB-HIV co-infection from Central Java, Indonesia. This study aimed to determine the factors associated with TBHIV/AIDS co-infection in Kedu, Central Java.

Subjects and Method: This study was a case control study conducted at general hospital in Kedu, Central Java. A sample of 152 patients with HIV was selected for this study consisting those with and without TB-HIV co-infection. The dependent variable was TB-HIV/ AIDS co-infection. The independent variable were education level, history of TB contact, BCG immunization status, opportunistic infection, adherence to treatment, drug taking supervisor support, and community health worker support. The data were collected from medical record and questionnaire. The data were analyzed by a multiple logistic regression.

Results: TB-HIV/AIDS co-infection was associated with low education ( $\mathrm{OR}=$ $4.70 ; \mathrm{CI}=95 \% ; 2.11$ to $10.47 \mathrm{p}=0,001)$, history of $\mathrm{TB}$ contact $(\mathrm{OR}=3.75 ; \mathrm{CI}=95 \%$; 1.26 to $5.72 ; \mathrm{p}=0.01)$, abscence of $\mathrm{BCG}$ immunization $(\mathrm{OR}=3.59 ; \mathrm{CI}=95 \% ; 1.07$ to $6.23 ; \mathrm{p}=0.033)$, opportunistic infection $(\mathrm{OR}=3.42 ; \mathrm{CI}=95 \% ; 1.23$ to $5.89 ; \mathrm{p}=$ o.010), non-adherence to treatment $(\mathrm{OR}=5.15 ; \mathrm{CI}=95 \% ; 1.50$ to $7.16 ; \mathrm{p}=0.001)$, lack of drug taking supervisor support $(\mathrm{OR}=4.61 ; \mathrm{CI}=95 \% ; 1.94$ to $10.50 ; \mathrm{p}=$ 0.001), and lack of community health worker support ( $\mathrm{OR}=4.51 ; \mathrm{CI}=95 \% ; 1.94$ to 10.50; $\mathrm{p}=0.001$ ).

Conclusion TB-HIV/AIDS co-infection is associated with low education, history of TB contact, abscence of BCG immunization, opportunistic infection, nonadherence to treatment, lack of drug taking supervisor support, and lack of community health worker support.
\end{abstract}

Keywords: risk factors, Tuberculosis-HIV/AIDS co-infection

\section{Correspondence:}

Tuti Susilowati. Doctoral Program in Medical and Health Sciences, Universitas Diponegoro, Semarang, Central Java. Email: Iyya_salaman@yahoo.co.id.

Mobile: 081357337149 